\title{
6. SOCIAL DETERMINANTS OF HEALTH
}

The context in which children live their lives, including the family, school, and community environments-and the interactions among these-is crucial to their health and wellbeing. In order to examine some of the social determinants of child health, the New South Wales Child Health Survey 2001 asked parents or carers of children to report on family functioning; access to social support; social capital; attendance at childcare, preschool, or school; and other childhood activities outside of these environments.

\section{Family Functioning}

The ability of a family to function well affects the health and wellbeing of children within the family. Family functioning affects many aspects of family life, including acceptance of individuals, degree of consensus on decisions, communication, and the ability to solve day-today problems. ${ }^{1}$ How a family functions is influenced by many factors, including quality of relationships; the health of family members; and the presence of life stresses, work, and finance. The enhancement of family and social functioning is a national and state priority for children. ${ }^{2,3}$

In the New South Wales Child Health Survey 2001, parents or carers of children aged 0-12 years were asked 14 questions from the McMaster Family Assessment Device, a questionnaire about family functioning that was used in the Western Australian Child Health Survey 1993. ${ }^{1}$ The tool generates a score between one and four, with one reflecting healthy functioning and four reflecting unhealthy functioning. ${ }^{4}$ Unhealthy family function relates to avoiding discussing concerns or fears, having lots of bad feelings within the family, not being able to turn to each other for support or to confide in each other, not being able to talk about sadness or express feelings to each other, difficulty in making decisions, not accepting family members as they are, and difficulty planning family activities. ${ }^{4}$

The median score for family functioning was 1.65, which reflects high levels of healthy family functioning overall. Families experiencing healthier family functioning than the median for the population included those where the mother had tertiary level qualifications (1.58), where all children in the family were under five years (1.58), and where the family was in the least socially-disadvantaged quintile by SEIFA index of postcode (1.59).

\section{References}

1. Zubrick SR, Silburn SR, Garton A, Burton P, Dalby R, Carlton J, et al. Western Australian Child Health Survey 1993-Developing health and wellbeing into the nineties. Perth: Western Australia Australian Bureau of Statistics and the Institute for Child Health Research, 1995.

2. Child, Adolescent and Family Health Service. Health Goals and Targets for Australian Children and Youth. Canberra: Child, Adolescent and Family Health Service and Department of Human Services and Health, 1992.
3. NSW Department of Health. The Start of Good HealthImproving the health of children in NSW. Sydney: NSW Department of Health, 1999.

4. Epstein NB, Baldwin LM, Bishop DS. The McMaster Family Assessment Device. Journal of Marital and Family Therapy1983; 9: 171-180.

\section{Social Support}

Social support includes support with parenting, feeling there are other people with which to share problems, and feeling close with another person. Social support is particularly relevant to disadvantaged parents or carers; and to those with physical problems or with mental health problems such as postnatal depression. Social support is known to affect a range of health and social outcomes for children, including rates of child injury in families with disadvantaged mothers. ${ }^{1}$ Olds et al. found that, for unmarried mothers on low income, frequent and targeted home visits (health services received in the home) by prenatal and early childhood nurses reduced the number of subsequent pregnancies; the use of welfare services; and the problems of child abuse and neglect, which are associated with the use of drugs and alcohol and criminal behaviour. ${ }^{2}$ Families First is a NSW Government policy that supports universal visiting by volunteers and health professionals, to increase social support for parents. ${ }^{3}$

In the New South Wales Child Health Survey 2001, parents or carers of children aged 0-12 years answered six questions about their relationships and support from others. These questions were previously used in the National Longitudinal Survey of Children in Canada. ${ }^{4}$

Five per cent of parents or carers reported that they would not have anyone to help them if something went wrong; 6.8 per cent reported there is no-one they feel comfortable with talking about problems; and 11.1 per cent reported they lack a feeling of closeness with another person. Parents or carers in urban areas reported higher levels of lack of social support. In urban areas, 5.2 per cent reported there was no one to help them if something went wrong compared iwth 4.5 per cent in rural areas; 7.0 per cent (urban) versus 6.1 per cent (rural) reported there was noone they feel comfortable with talking about problems; and 11.4 per cent (urban) versus 10.2 per cent (rural) reported that they lacked a feeling of closeness with another person.

Most parents or carers (95.7 per cent) reported that they had friends who make them feel safe secure and happy; 96.6 per cent reported there was someone they could trust and to whom they could turn for advice if they were having problems; and 96.9 per cent reported there were people they could count on in an emergency.

\section{References}

1. Hodnett ED, Roberts I. Home-based social support for socially disadvantaged mothers. Cochrane Database Syst Rev. 2000(2): CD000107. 


\section{FIGURE 1}

\section{RECIPROCITY AND NEIGHBOURHOOD CONNECTIONS BY URBAN-RURAL AREA HEALTH SERVICE OF RESIDENCE, PARENTS OR CARERS WITH CHILDREN AGED 0-12 YEARS, NSW, 2001}
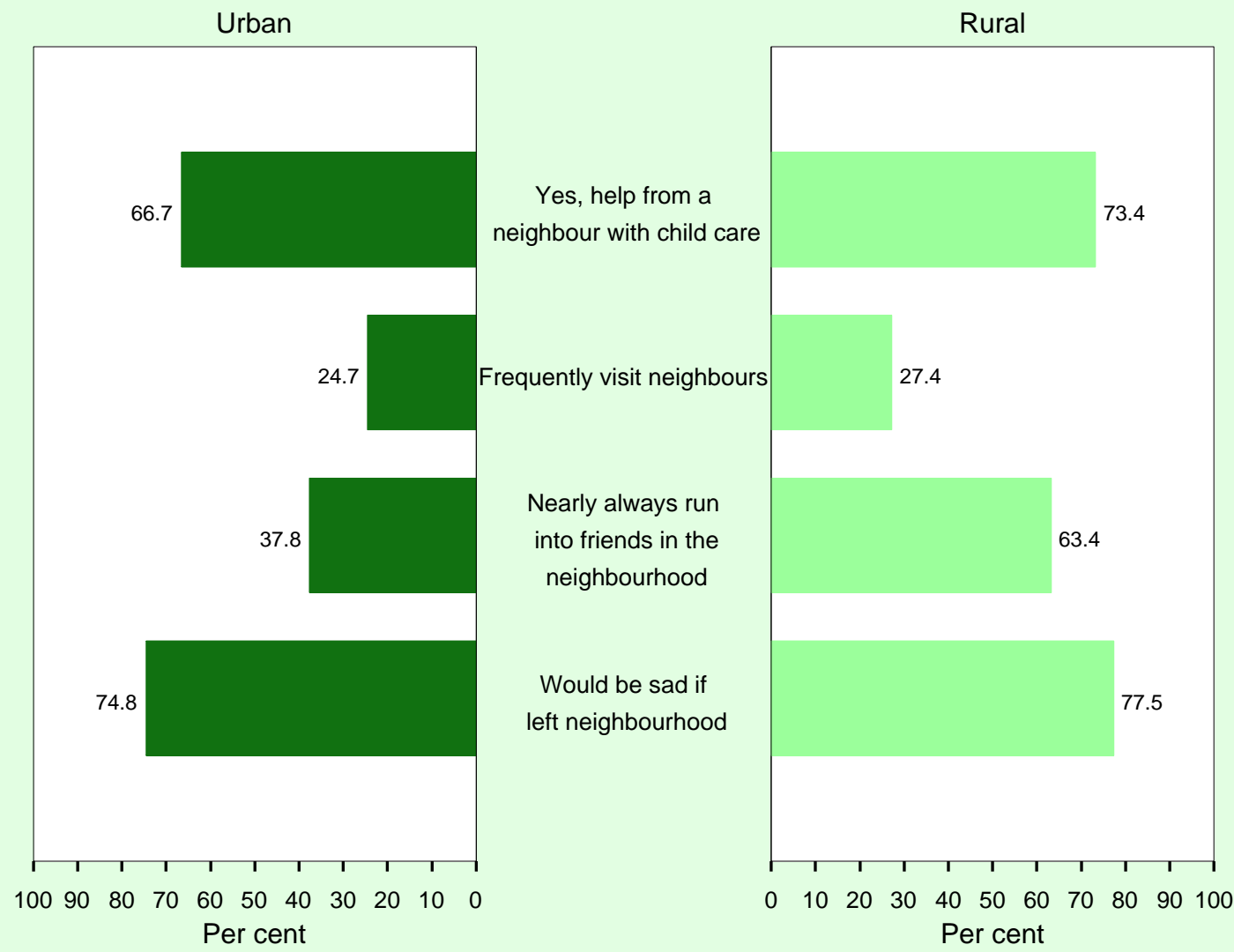

Note: Health areas in Greater Sydney, Hunter, and Illawarra were classified as urban. Estimates based on 9425 respondents.

Source: New South Wales Child Health Survey 2001 (HOIST). Centre for Epidemiology and Research, NSW Department of Health.

2. Olds DL, Eckenrode J, Henderson CR, et al. Long term effects of home visitation on life course and child abuse and neglect: Fifteen year follow up of a randomized trial. JAMA 1997; 78: 637-643.

3. The Families First Resource Kit. Sydney: NSW Cabinet Office, 2000 Web site www.parenting.nsw.gov.au, accessed 24 April 2002.

4. Child Support Team. National Longitudinal Survey of Children, Child Support. Ottawa: Canadian Department of Justice, 1993.

\section{Social Capital}

The term 'social capital' refers to the institutions, relationships, and norms, that shape social networks, foster trust, and facilitate coordination and cooperation for mutual benefit. ${ }^{1}$ A key concept of social capital is the notion of interlocking networks of relationships between individuals and groups.

In the New South Wales Child Health Survey 2001, all parents and carers were asked questions that relate to aspects of social capital. The questions were limited to the domains of reciprocity, neighbourhood connection, safety, trust, and community participation, which are consistent with those used in a recent study that compared five communities in NSW. ${ }^{2}$ One new question was included-whether the respondent would be sad if they had to leave their neighbourhood.

\section{Social reciprocity and neighbourhood connection}

Social reciprocity and neighbourhood connection are defined as a combination of short-term altruism and longterm self interest - where people help each other or act for the benefit of other people at a personal cost, with the general expectation that this help will be returned in the future when they might need help themselves. ${ }^{2}$

Parents or carers of children aged 0-12 years were asked three questions regarding reciprocity and neighbourhood connections. Approximately two-thirds (68.3 per cent) responded that they could get help from a neighbour to care for a child, approximately one-quarter ( 25.3 per cent) said they frequently visited neighbours, nearly half (43.9 per cent) responded that they nearly always run into friends in the neighbourhood, and approximately three- 


\section{FIGURE 2}

STRONGLY AGREE OR AGREE THAT THE LOCAL AREA IS SAFE, BY URBAN-RURAL AREA HEALTH SERVICE OF RESIDENCE, PARENTS OR CARERS WITH CHILDREN AGED 0-12 YEARS, NSW, 2001
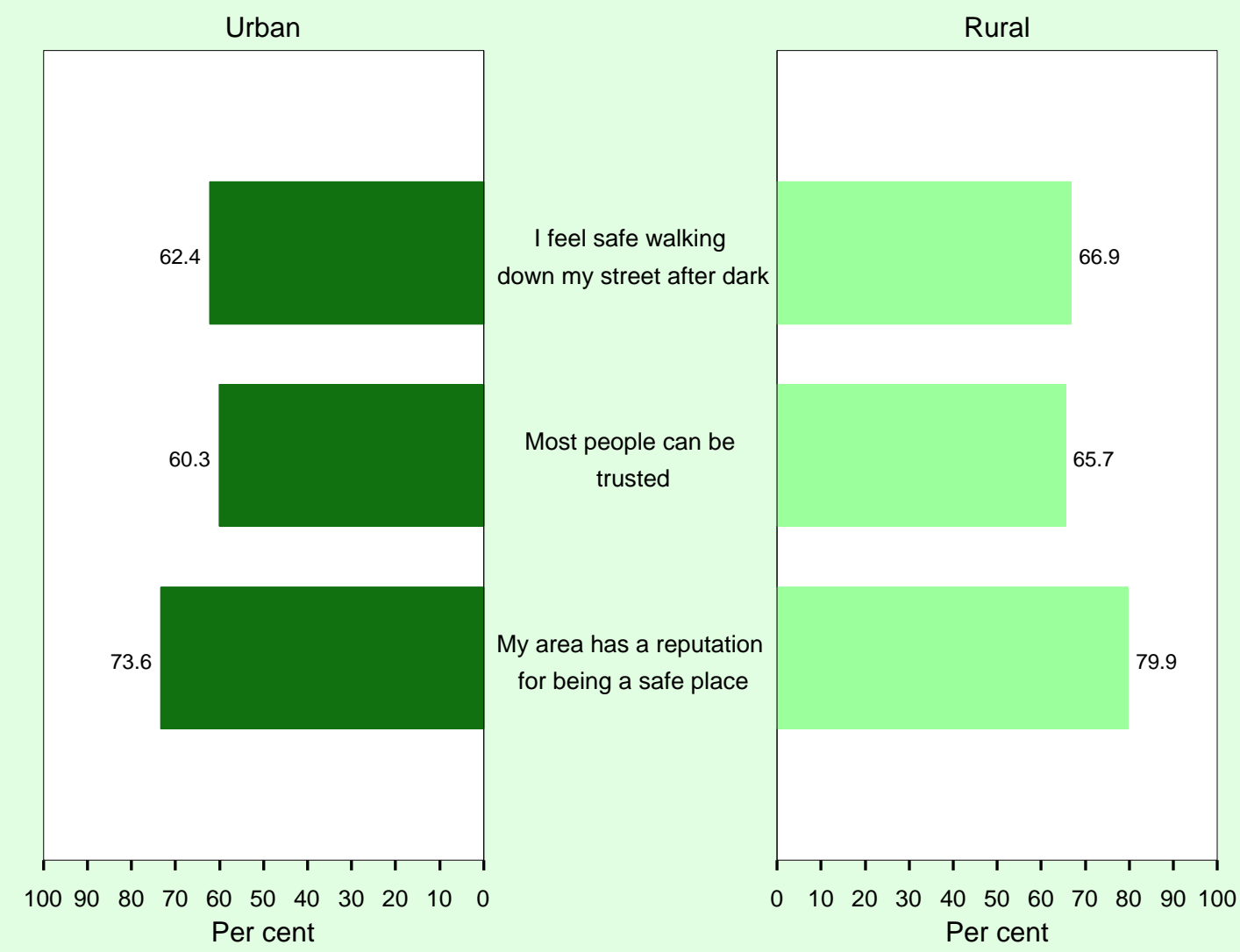

Note: Health areas in Greater Sydney, Hunter, and Illawarra were classified as urban. Estimates based on 9425 respondents.

Source: New South Wales Child Health Survey 2001 (HOIST). Centre for Epidemiology and Research, NSW Department of Health.

quarters (73.5 per cent) reported that they would be sad if they left their neighbourhood. Respondents in rural areas reported more reciprocity and neighbourhood connection, compared with urban areas; the main difference being the frequency of respondents who nearly always ran into friends in the neighbourhood-63.4 per cent in rural areas compared with 37.8 per cent in urban areas (Figure 1).

\section{Feelings of trust and safety}

Trust involves a willingness to take risks in a social context. This willingness is based on a confidence that others will respond as expected and will act in mutually supportive ways-or at least that others will not intend harm.

Parents or carers of children aged 0-12 years were asked three questions regarding trust and safety. Approximately two-thirds (63.5 per cent) of respondents reported that they felt safe walking down the street after dark, 61.6 per cent reported that most people can be trusted, and threequarters (75.1 per cent) reported that their area has a reputation for being safe. A higher proportion of respondents from rural areas, compared with urban areas, reported feeling safe and trusting of others, with the most difference shown for the response to the statement that their area has a reputation for being a safe place-79.9 per cent in rural areas compared with 73.6 per cent in urban areas (Figure 2).

\section{Participation in local community}

Social capital is not generated by individuals acting on their own; it is generated by people in communities engaging with others through a variety of associations that are both voluntary and equitable. Participation in the local community depends on a tendency among people to be social and to form new associations and networks.

Parents or carers of children aged 0-12 years were asked three questions regarding participation in the local community. Forty (40.4) per cent reported they had 'helped out' at a local group or organisation; 68.2 per cent reported they had attended a local community event; and 40.0 per 


\section{FIGURE 3}

\section{PARTICIPATION INTHE LOCAL COMMUNITY_VERY OR SOMEWHAT ACTIVE, BY AGE GROUP, PARENTS OR CARERS WITH CHILDREN AGED 0-12 YEARS, NSW, 2001}
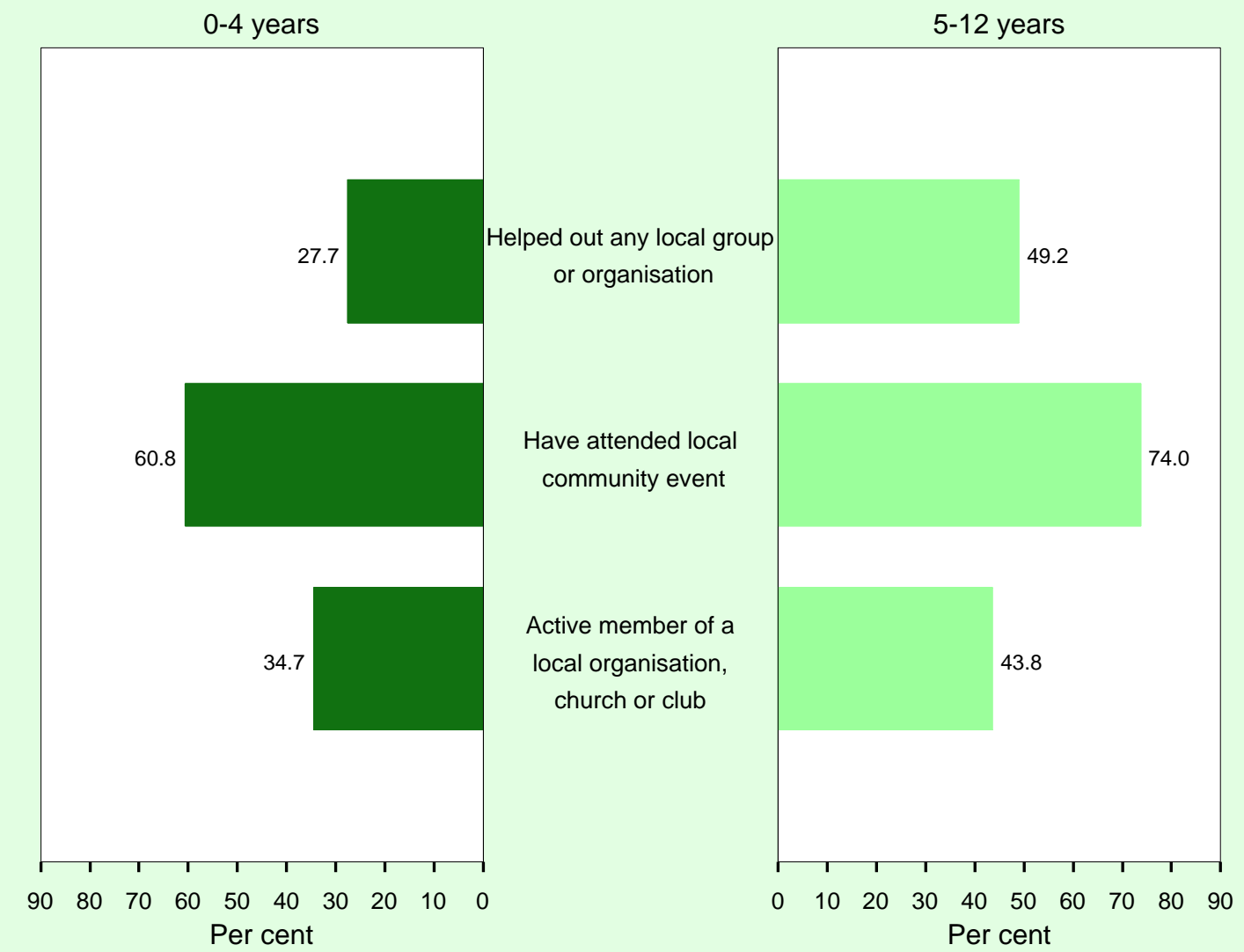

Note: Estimates based on 9425 respondents.

Source: New South Wales Child Health Survey 2001 (HOIST). Centre for Epidemiology and Research, NSW Department of Health.

cent reported they were active members of local organisations, churches, or clubs. Respondents with children aged 5-12 years, and respondents from rural areas, reported higher rates of participation in the local community. The greatest difference was in helping a local group or organisation-49.2 per cent for parents or carers of children aged 5-12 years, compared with 27.7 per cent for children aged 0-4 years (Figure 3 ); and 45.8 per cent for rural areas compared with 38.6 per cent for urban areas.

\section{References}

1. The World Bank Web Site at www.worldbank.org/poverty/ capital/whatsc.htm accessed 19 July 2002.

2. Onyx J, Bullen P. Measuring Social Capital in Five Communities in NSW: An analysis. Sydney: Centre for Australian Community Organisations and Management, 1997.

\section{Childhood activities}

On a daily basis, children are involved in different arenas that affect their physical, emotional, and social wellbeing including school, family, and extracurricular activities. Schools teach children skills such as reading, writing, and teamwork, which they need to participate in community life. Family is the first place children learn about sharing and cooperation. For children, extracurricular activities-provided through clubs, sporting teams, and informal groups of friends-are a major source of social capital. Children pursue common goals, and obtain a feeling of solidarity and commitment with their peers, through their involvement in these activities. ${ }^{1}$

In the New South Wales Child Health Survey 2001, parents or carers of children aged 4-12 years were asked two questions about children's extracurricular activities, including their child's favourite activities and places where their child plays when not at childcare, preschool, or school. 
Favourite activities when not at childcare, preschool, or school

Parents and carers reported that the most common favourite activities among children were organised sport (16.6 per cent), computer and video games (10.3 per cent), bike riding (8.8 per cent), playing with toys at home (8.7 per cent), and drawing and colouring-in (6.9 per cent). Among males, the most commonly reported favourite activities were: organised sport (22.5 per cent), computer and video games (16.3 per cent), bike riding (12.0 per cent), playing at home with toys (8.1 per cent), and informal sport (7.9 per cent). In contrast, the most frequently reported favourite activities among females were: drawing and colouring-in (11.2 per cent), organised sport (10.5 per cent), playing with toys at home ( 9.4 per cent), dancing (8.1 per cent), and reading ( 7.7 per cent). The most commonly reported favourite activities of children aged 4-7 years were: playing with toys at home (14.3 per cent), drawing and colouring-in (12.0 per cent), bike riding (11.1 per cent), playing outside (9.1 per cent) and organised sport (8.1 per cent). The most frequently reported favourite activities of children aged 8-12 years were: organised sport (22.6 per cent), computer and video games (12.8 per cent), bike riding (6.9 per cent), reading (6.7 per cent), and informal sport (6.2 per cent).

\section{Places where children play when not at childcare, preschool, or school}

The most frequently reported locations where children were reported to play were: in the back yard of their home (68.8 per cent), inside the house (57.5 per cent), in the park (29.0 per cent), at the home of a friend or relative ( 23.7 per cent), at the home of a neighbour (21.8 per cent), and in the street (10.6 per cent). Children aged 8-12 years were almost twice as likely to play in the street, compared with children aged 4-7 years (13.1 per cent versus 7.4 per cent). Females more frequently played inside the house (61.4 per cent) and at friends or relatives (25.9 per cent), compared to males who more frequently played in the backyard (68.8 per cent) and in the park (32.8 per cent).

\section{Reference}

1. Goss K. Better Together: Report of the Saguaro Seminar on Civic Engagement in America, Cambridge, Mass: John F. Kennedy School of Government, Harvard University, 2000. Web site: www.bettertogether.org, accessed 3 May 2002.

\section{Attendance at childcare, preschool, or school}

The link between health and education has been widely reported. Participation in appropriate early care and educational settings has been associated with enhanced cognitive and language development-and with emerging literacy.

Education about and awareness of health issues is also known to contribute to children's health. In addition, health status is a major determinant of educational achievement; children in good health are more likely to achieve higher educational goals. ${ }^{1}$

\section{Attendance at childcare}

In the New South Wales Child Health Survey 2001, parents and carers of children aged 0-5 years were asked about childcare attendance on a regular basis. 'Childcare' was defined as formal (that is, long day care or family day care) or informal (that is, care by relatives, friends, paid babysitters, or nannies). 'Regular basis' was considered to be childcare for at least half-a-day per week. Approximately half (52.6 per cent) of all children aged $0-5$ years were reported to have attended childcare, with 43.0 per cent currently attending childcare. Of the children currently attending childcare, 19.8 per cent had started childcare when they were less than six months of age, 46.4 per cent had started childcare by one year of age, and 73.4 per cent had started childcare by the age of two years. The main types of childcare used by families were: long day care (37.7 per cent); grandparents (30.4 per cent); family day care (15.6 per cent), and other relatives or family (9.5 per cent). Compared with mothers with no tertiary qualifications, mothers who had tertiary qualifications were more likely to report higher use of childcare in the past (62.8 per cent compared with 48.3 per cent) and higher current use of childcare (53.5 per cent compared with 38.5 per cent).

\section{Attendance at preschool and school}

Parents and carers of children aged 3-6 years reported preschool attendance and parents and carers of children aged 4-12 years reported school attendance. Preschool was defined as a place being attended between 9.00 a.m. and 3.00 p.m. at least once per week before the child starts full-time school. Overall, 53.0 per cent of children aged three years were currently attending preschool, 72.7 per cent of children aged four years and 17.0 per cent of children aged five years were currently attending preschool. The majority of children not attending preschool were either attending childcare (20.2 per cent of children aged three years, 11.7 per cent of children aged four years and 0.05 per cent of children aged five years) or attending school (8.4 per cent of children aged four years and 80.0 per cent of children aged five years). Ninety-nine per cent of children aged 6-12 years were currently attending school. Of the children currently attending school, 69.0 per cent were attending public schools, 19.9 per cent were attending Catholic schools, and 10.2 per cent were attending other private schools.

\section{Reference}

1. National Health and Medical Research Council. Effective school health promotion: Towards health promoting schools. Canberra: NHMRC, 1996. 